\title{
A vivência de uma intervenção docente: reflexões sobre o ensino e a aprendizagem de Matemática
}

\section{The experience of a teaching intervention: reflections on teaching and learning of Mathematics}

\author{
Vinícius Pazuch* \\ Cátia Maria Nehring*
}

\begin{abstract}
Resumo: Este artigo reflete sobre uma vivência de intervenção docente, na forma de Estágio de Docência no Ensino Superior, no Curso de Licenciatura em Matemática de uma universidade do interior do Rio Grande do Sul, Brasil. A intervenção ocorreu em uma disciplina de Prática de Ensino, que teve como centralidade a discussão dos Parâmetros Curriculares Nacionais do Ensino Fundamental. Esta produção é marcada por momentos, que, embora, separados, se complementam, se articulam. Foram feitas análises das observações de aula da professora titular e das atividades usadas pelo professor estagiário e, por fim, análises de registros dos licenciandos, advindos da reflexão das atividades realizadas na intervenção. As contribuições provenientes deste artigo são, principalmente, as articulações imprimidas pelos licenciandos entre os campos, blocos de conteúdos e conceitos de matemática do Ensino Fundamental. As articulações construídas revelam possibilidades de tratamento dos conceitos matemáticos na licenciatura e projetam os licenciandos como professores de matemática da Educação Básica.
\end{abstract}

Palavras-chave: Prática de ensino. Matemática no Ensino Fundamental. Educação Matemática.

\begin{abstract}
This paper proposes a reflection on the experience of a teaching intervention, in the format of higher education teaching training, in the Mathematics course of a university in Rio Grande do Sul, Brazil. The intervention was carried out in the teaching practice subject, which focused on the discussion of Brazilian National Curricular Parameters for Basic Education. This production is marked by moments, which, although separate are complementary and interrelated. The lessons given by the professional teacher were observed and analyzed as well as the activities employed by the teacher in pre-service training and these were followed by analysis of the undergraduate students' registers, resulting from the reflections upon the activities carried out during the intervention. Contributions originated in this paper are mainly
\end{abstract}

\footnotetext{
* Mestre em Educação nas Ciências pela Universidade Regional do Noroeste do Estado do Rio Grande do Sul. E-mail: <viniuch@hotmail.com>

** Professora da Universidade Regional do Noroeste do Estado do Rio Grande do Sul. E-mail: <catia@unijui. edu.br>
} 
the links found by the undergraduate students among the fields, blocks of content and concepts of Mathematics in elementary school. The interrelations built reveal possibilities for the treatment of mathematical concepts in teacher education and project the trainees as elementary school mathematics teachers.

Keywords: Teaching practice. Mathematics in Elementary School. Mathematics Instruction.

\section{Considerações iniciais - pressupostos teóricos e metodológicos}

A vivência relatada tem a pretensão de dialogar com o leitor no sentido de refletir sobre processos de ensinar e aprender matemática, pois infere a respeito de entendimentos teóricos e práticos sobre a intervenção docente (Estágio de Docência na Graduação ${ }^{1}$ ) em uma disciplina de Prática de Ensino, do Curso de Licenciatura em Matemática de uma universidade do interior do estado do Rio Grande do Sul, Brasil.

O artigo é organizado elencando momentos que passam desde o planejamento feito pela professora titular, da intervenção até a ação dos sujeitos envolvidos (professor e estudantes), proporcionando, em nosso entendimento, contribuições e possibilidades de intervenção na prática docente no Ensino Superior. A prática docente é entendida pelo modo, pelas interações, pelos encaminhamentos e pelas justificativas teóricas, dadas pelo professor (primeiro autor).

A escolha da disciplina - Prática de Ensino III: Matemática no Ensino Fundamental - foi devido à proximidade com a matemática do Ensino Fundamental, objeto de pesquisa na dissertação de mestrado (PAZUCH, 2010) e, também, pelo fato de a disciplina possuir estreita relação com a elaboração de planejamentos de ensino, discussão de artigos relacionados ao ensino de matemática, especialmente os ligados aos Parâmetros Curriculares Nacionais (PCN) do Ensino Fundamental e à organização curricular da Educação Básica.

Nessa perspectiva, inicialmente, apresentamos um resgate teórico da formação de professores, destacando algumas vertentes teóricas que podem "costurar" a essência desta produção escrita, que é apontar contribuições para o ensino e a aprendizagem de matemática, para a profissão docente no que se refere aos seus saberes, os quais, em nossa concepção, fundamentam a ação em sala de aula, seja na Educação Superior ou na Educação Básica.

O segundo momento do artigo é permeado pela narrativa da observação de aulas proferidas pela professora titular da disciplina (Prática de Ensino

\footnotetext{
${ }^{1}$ O Estágio de Docência na Graduação é um componente curricular do Curso de Pós-Graduação da Universidade.
} 
III: Matemática no Ensino Fundamental) e pelo planejamento de intervenção docente, desenvolvido com uma turma da Licenciatura em Matemática, em que são apresentadas as atividades, os procedimentos e os recursos didáticos usados.

No terceiro momento, explicitamos o planejamento da intervenção docente, a qual foi feita pelo primeiro autor, destacando a processualidade e os caminhos escolhidos para explicitar as atividades de ensino, vivenciadas e discutidas com o licenciandos, em duas aulas (23/04/2009 e 30/04/2009).

No quarto e último momento são apresentadas reflexões e contribuições, baseadas nos entendimentos dos licenciandos sobre três atividades propostas. Neste artigo, uma das atividades é tomada como central (atividade da "caixa de bombons") e articula um processo de encadeamento dos campos da matemática, dos blocos de conteúdos, para assim trabalhar com os conceitos, que é uma das proposições dos PCN. É necessária “[...] uma articulação interna aos conteúdos próprios da Matemática, quando se trata de relacionar números, expressões algébricas, geometria e medidas [...]" (PAIS, 2006, p. 52). A atividade da "caixa de bombons" é olhada a partir do registro dos licenciandos, revelando os sentidos que eles verbalizam em relação à imbricação dos campos da matemática, sendo que as atividades foram desenvolvidas coletivamente.

A organização deste ensaio é marcada por momentos que, embora separados, se complementam, pois a abordagem teórica e as compreensões/ análises da intervenção docente se inter-relacionam na perspectiva de apontar recursos didáticos (PAIS, 2006), procedimentos metodológicos/estratégias e saberes (TARDIF, 2002) que possam sustentar a prática docente do professor (no Ensino Superior) e dos futuros professores (Educação Básica) em relação ao ensino e à aprendizagem de matemática.

\section{Formação de professores de matemática: práticas e saberes docentes}

O Curso de Licenciatura em Matemática da universidade tem como objetivos centrais, estabelecidos pelo Projeto Político Pedagógico (PPP):

- Contribuir para a melhoria da educação praticada nas escolas de Educação Básica da região de abrangência da Universidade, mediante à formação/ capacitação de professores de matemática, possibilitando a construção de conhecimentos, a reelaboração de concepções, o desenvolvimento de posturas e atitudes, enquanto profissionais munidos do princípio da educação continuada e qualificada.

- Capacitar os futuros professores para atuar em Matemática no Ensino Fundamental e Médio, desenvolvendo formas de leitura "crítica" da realidade, na busca de novos tipos de relações entre a sociedade, a educação, a tecnologia 
e o ambiente, de forma a contribuir para a construção de uma vida melhor, para todos os sujeitos envolvidos no processo educativo e onde este se reflete (PPP, 2009, p. 2).

$\mathrm{Na}$ perspectiva de contribuição para a Educação Básica, o Curso de Matemática Licenciatura (PPP, 2009) contempla uma estrutura curricular articulada em dois grandes módulos: Formação científico-cultural (núcleo específico, núcleo comum de formação humanística e núcleo comum das licenciaturas) e Formação profissional (núcleo comum das licenciaturas, componentes curriculares de práticas profissionais e componentes curriculares de estágios supervisionados).

Sem a pretensão de aprofundar esta discussão, mas de compreender os eixos que compõem estes grandes módulos, discorremos sobre a especificidade que representa cada eixo no curso.

O Núcleo Específico têm como objetivo desenvolver a capacidade de expressão de idéias, relações e propriedades da Matemática.

Os componentes curriculares do Núcleo de Formação Humanistica constroem uma visão crítica da realidade educacional, re-elaborando concepções de Sociedade, Educação, Ciência, Tecnologia, Escola, Política e Economia.

Os componentes curriculares do Núcleo Comum das Licenciaturas se caracterizam pela discussão geral do professor. Sua importância e a necessidade tem razões institucionais e históricas de caráter político-pedagógico de Formação do Professor.

O módulo da Formação Profissional visa construir um suporte teórico, que associado à vivência e à análise da prática pedagógica e dos fenômenos da escola, forme um ciclo de contínua alimentação. A teoria auxilia a prática, porém, a prática é complexa. Bem mais do que a teoria pode prever. Portanto a teoria precisa ser remodelada constantemente, sob a luz da ação, da razão e através de uma dinâmica investigativa sobre a prática (ação-reflexão-ação). O Módulo da Formação Profissional envolve componentes que compõem as Práticas Profissionais e componentes curriculares que compõem os Estágios Supervisionados (PPP, 2009, p. 9-11, grifo dos autores).

Embora os módulos possuam seus eixos, para uma efetiva formação inicial do professor de matemática é fundamental que as especificidades destacadas se completem e promovam um ensino de qualidade. Por isso, os módulos de formação científico-cultural e da formação profissional "[...] deverão estar estreitamente articulados entre si e relacionados com a realidade educacional, visando à formação do educador matemático explicitado nos objetivos e princípios norteadores do projeto de curso" (PPP, 2009, p. 12).

Em face à dinâmica do curso, a realização desta intervenção docente intenciona contribuições para a formação inicial dos licenciandos. Assim, 
inferimos que os conceitos, os recursos didáticos, os procedimentos metodológicos implicados na intervenção promovem uma sincronia dos aspectos teóricos com a prática docente. Entendemos prática docente como o movimento de ensinar e aprender matemática, estabelecido pela mobilização de saberes disciplinares, curriculares e experienciais (TARDIF, 2002) e pela aprendizagem dos licenciandos.

Neste artigo, com base em Tardif (2002) olhamos para o saber disciplinar (matemática), que emerge das tradições culturais e da sociedade e para o saber curricular, que corresponde "[...] aos discursos, objetivos, conteúdos e métodos a partir dos quais a instituição escolar categoriza e apresenta os saberes sociais por ela definidos [...]" (TARDIF, 2002, p. 38). Particularmente, traçamos algumas relações com tais saberes ao longo do artigo.

Clarificamos que Tardif (2002) promove uma tipologia dos saberes, entre eles, os profissionais, os pedagógicos, os disciplinares, os curriculares e os experienciais, os quais formam os saberes docentes. Salientamos que tais saberes e outros possam ser identificados, neste ensaio, porém, a intenção não é classificar, mas apontar algumas contribuições no que tange à constituição das práticas e dos saberes a partir de uma vivência, estabelecendo um diálogo com os processos de ensinar e de aprender matemática.

A nossa preocupação é promover o diálogo entre estes tipos de saberes, intensificando, através dos registros dos licenciandos (item 4), a articulação entre os campos, os blocos de conteúdos e os conceitos da própria matemática, desencadeada por atividades de ensino vivenciadas com recursos didáticos e por procedimentos metodológicos indicados pelos PCN, documento central de estudo na disciplina em questão.

A fim de clarificar o entendimento sobre campos da matemática e blocos de conteúdos, os PCN apontam que há um consenso a fim de que a organização curricular de matemática no Ensino Fundamental contemple o bloco dos números e das operações (no campo da aritmética e da álgebra), o bloco do espaço $e$ das formas (no campo da geometria), o bloco das grandezas e das medidas (que permite interligações entre os campos da aritmética, da álgebra e da geometria, além de outros campos do conhecimento) como também o bloco tratamento da informação, que pode estar agregado a outros campos e blocos (BRASIL, 1998). Assim, enfatizamos que cada bloco de conteúdo pode ser tratado de forma singular/específica, mas que precisam estar conectados a outros blocos e campos da matemática, identificando a complexidade do cotidiano dos sujeitos, e os papéis que os procedimentos matemáticos podem desencadear na compreensão e interpretação do mundo. 


\section{Narrativas de aulas de prática de ensino}

A disciplina de Prática de Ensino III: Matemática no Ensino Fundamental apresenta como objetivo central:

Caracterizar a educação matemática no ensino fundamental a partir da análise de propostas de ensino, de livros didáticos, de Documentos Oficiais e das situações de interação com a escola. Enfoque para o ensino e aprendizagem de matemática com a discussão de conceitos de $5^{\mathrm{a}} \mathrm{e} 6^{\mathrm{a}}$ séries, nos planejamentos de aulas, considerando os conceitos de didática que envolvem as ações pedagógicas. Proporcionando ao licenciando a observação, a problematização e a análise das práticas, com ênfase nos planejamentos de ensino (PPP, 2009, p. 38, grifo dos autores).

Desta maneira, neste tópico, apresentamos episódios da observação de aulas da referida disciplina. O planejamento da professora titular nesta disciplina se deu principalmente a partir da ação dos sujeitos (licenciandos). Com isso, não estamos suprimindo a importância do planejamento elaborado a priori, pelo contrário, é esse planejamento que sustenta os diálogos estabelecidos entre a professora e os licenciandos.

A ação dos licenciandos é expressa através de depoimentos, de interferências, questionamentos, não somente aqueles "controlados" e feitos pela professora, mas outros, advindos do interesse e de práticas docentes já vivenciadas por alguns dos licenciandos.

Nesta narrativa, o objetivo principal é contemplar algumas passagens das aulas da professora titular, resgatando encaminhamentos, estratégias, recursos, atividades, conceitos abordados, concatenando com a intervenção docente do professor estagiário (primeiro autor do artigo - objeto de discussão no próximo tópico).

Um dos objetivos de discussão desta disciplina de Prática de Ensino é estudar os PCN. Entretanto, a professora expressa, primeiramente, a dinâmica das disciplinas de Prática de Ensino e o papel atrelado destas no currículo da Licenciatura em Matemática da universidade, com a intenção de situar os licenciandos.

Posteriormente, a professora propõe uma atividade de leitura Chutei a bola no ângulo, que consiste em uma narrativa sobre uma aula de matemática que enfatiza o conceito de ângulo. Mediante a leitura e o diálogo estabelecido com os licenciandos, a professora problematiza essa narrativa, trazendo outros elementos e exemplos que propiciaram aos licenciandos pensar sobre o conceito "ângulo".

Os encaminhamentos dados pela professora, após a leitura e discussão do texto aos licenciandos, foram estes: 
Ideias a partir do título;

Pontos destacados no texto;

Conceitos matemáticos;

Entendimento do conceito de ângulo;

Como aprendeu o conceito de ângulo?

Como aconteceu a transposição da atividade prática ao registro?

Houve a formalização do conceito?

Papel do planejamento na proposição, encaminhamento e avaliação;

Como trabalhar de maneira diferente do proposto no texto?

(Notas de aula da professora titular - 05/03/2009).

As questões elaboradas pela professora têm a pretensão de mobilizar os licenciandos para a compreensão do conceito de ângulo. É nesse sentido que, na aula seguinte (12/03/2009), a professora traz materiais manipulativos (régua, compasso, tesoura, papel sulfite e transferidor) para os próprios licenciandos conceituar ângulo. Ainda, para pensar sobre o conceito e diferentes maneiras de trabalhar com ângulos, a professora discute um texto complementar (BAIRRAL, 2002).

A finalização da aula referente ao conceito de ângulo foi marcada pelo uso de diferentes recursos, instigando os licenciandos para a formulação de seu próprio conceito de ângulo. Esta proposição da professora corrobora no saber disciplinar (matemático), ao mesmo tempo em que trabalha a noção de saber curricular, pois o ambiente de planejamento e compreensão dos conceitos a serem ensinados pelos licenciandos em seu futuro trabalho docente foi desencadeado pela investigação.

Refletir sobre o currículo de matemática se constitui uma das chaves para o ensino. Nessa perspectiva, nesta aula a professora usou Pires (2000, 2007) para introduzir as implementações de reformas e as inovações curriculares no ensino de matemática. Pires (2007) considera o professor como o protagonista do processo de ensino e de aprendizagem, chamando atenção para a resistência dos professores para as inovações curriculares e a desarticulação existente a formação de professores e os processos de mudança, inovação e desenvolvimento curricular.

A professora expõe as temáticas (apresentação em slides) dialogando com os licenciandos, com a intencionalidade de incorporá-los nos aspectos teóricos contemplados por Pires $(2000,2007)$. A trajetória histórica das reformas (PIRES, 2007) busca evidenciar a relação entre implementação de inovações curriculares e o envolvimento de professores que ensinam matemática nesse processo.

O envolvimento dos professores na composição do currículo de matemática se apresenta como o foco principal (PIRES, 2007), a fim de torná-los 
sujeitos capazes de promover mudanças frente às novas demandas da sociedade globalizada, transformando as dimensões espaço-temporais da escola na busca permanente de ações e interações que desencadeiem o ensino e a aprendizagem dos estudantes em todos os níveis, especialmente na Educação Básica, lócus profissional dos licenciados, futuros professores de matemática.

O engajamento do professor na composição do currículo é um processo desafiador e complexo, implicando outras discussões que agregam o estudo das políticas públicas, das diretrizes curriculares, dos parâmetros curriculares, da própria formação docente e, sobretudo, do envolvimento dos professores de todos os níveis de escolaridade, principalmente, os da Educação Básica.

Aspectos concernentes à aula, também discutidos pela professora, foram as reformas curriculares (PIRES, 2007), as quais compreendem três grandes movimentos: Movimento da Matemática Moderna (MMM) 1965-1980, período marcante no ensino de álgebra e o abandono do ensino de geometria, em que não eram feitas conexões com o cotidiano; reformas lideradas pelas Secretarias Estaduais e Municipais de Ensino 1980-1994, movimento que tenta contrapor o MMM, contemplando questões relacionadas com aspectos avaliativos, com a implantação de três grandes temas: números, geometria e medidas, inclusão de temas geradores no currículo e aplicações no cotidiano; e a produção dos PCN - Parâmetros Curriculares Nacionais - a partir de 1995.

Assim, nas aulas (19/03/2009; 26/03/02009 e 02/04/2009) foram feitas discussões e reflexões acerca dos PCN. Para isto, a professora organizou apresentações de tópicos dos PCN, promoveu trabalhos, leituras e reflexões em pequenos grupos e no grande grupo, esquemas dos principais tópicos e registros escritos (por meio de trabalhos na sala de aula e extraclasse) de entendimentos dos licenciandos.

Pontualmente, a discussão dos PCN foi iniciada (19/03/2009) com preocupações advindas dos licenciandos, principalmente em como ensinar matemática na Educação Básica, preocupação de alguns que já atuaram ou que estão em sala de aula como professores e também daqueles que estavam fazendo estágio no Ensino Fundamental. Algumas das percepções dos licenciandos foram registradas e sinalizam os depoimentos a seguir:

Como vou ensinar?

Como vou incluir os conceitos nas atividades?

Como vou trabalhar os conteúdos?

Os professores trabalham muito no quadro, não trabalham com materiais, jogos, tecnologias... Esses métodos você acha aonde? O conceito eu sei, mas como eu ensino?

Não é o quê. Mas como?

(Depoimentos dos licenciandos - 19/03/2009, grifo nosso). 
Os questionamentos foram gerados em virtude de os PCN apontarem algumas possibilidades de trabalho docente diferenciadas. Essas possibilidades inferem sobre a abordagem conceitual partindo de atividades de ensino, tendo como recursos a resolução de problemas, tecnologias da informação e comunicação, história da matemática e modelagem matemática, por exemplo.

Os PCN de Ensino Fundamental apresentam uma divisão da matemática em três campos: álgebra, aritmética e geometria; e, ainda, a estatística, probabilidade e combinatória, que representam uma subdivisão da matemática, mas não são consideradas como um campo. Os campos estão organizados em blocos de conteúdos, a saber: números e operações; espaço e forma; grandez̧as e medidas e tratamento da informação.

A discussão sobre os campos, blocos de conteúdos e objetivos da matemática no Ensino Fundamental ocorreu (26/03/2009) com a explicação e esquema proposto (no quadro negro) pela professora, com o estabelecimento de diálogos com os licenciandos. A compreensão dos PCN aconteceu também a partir de olhares para a divisão do documento em ciclos, isto é, o Ensino Fundamental em 1998, quando os PCN foram elaborados, era organizado em ciclos, em que o $3^{\circ}$ ciclo (correspondente a $5^{\mathrm{a}}$ e $6^{\mathrm{a}}$ séries) e o $4^{\circ}$ ciclo (correspondente a $7^{\mathrm{a}}$ e $8^{\mathrm{a}}$ séries).

Entendimentos sobre essa organização dos PCN de Matemática para o Ensino Fundamental foram investigados no próprio documento. Essa investigação deu-se através da proposição de um trabalho em grupo (dois licenciandos), desenvolvido em sala de aula (02/04/2009). O trabalho foi organizado da seguinte forma pela professora:

Trabalho em duplas

a) Caracterização dos alunos/sujeitos do $3^{\circ}$ e $4^{\circ}$ ciclos.

b) Resumo dos objetivos, conteúdos/conceitos.

c) Relação possível entre os objetivos, conteúdos e conceitos. Para isso, escolha um objetivo de cada ciclo e de cada bloco e explore as possíveis relações entre conteúdos/conceitos/objetivos.

d) A partir desta relação, descreva um conteúdo/conceito.

(Notas de aula da professora titular - 02/04/2009).

A socialização dos trabalhos realizada (16/04/2009) pelos licenciandos, apontando dificuldades, comparações entre os conteúdos do $3^{\circ}$ e $4^{\circ}$ ciclos e entendimentos acerca das ligações entre blocos de conteúdos, conceitos e objetivos recaía sempre em aspectos inerentes à prática docente, ou seja, como ensinar matemática na Educação Básica, fazendo que os estudantes entendam matemática? Quais as estratégias? Recursos? Atividades? Como planejar? Estas e outras 
questões foram pinçadas na maioria das aulas observadas, caracterizando que as práticas de ensino possuem a ideia de sistematização dos conceitos e entendimentos teóricos ligados ao lugar em que acontece o ensino: a sala de aula. Em outras palavras, a abordagem teoria e prática estão imbricadas.

\section{A intervenção docente: planejamento e caminhos escolhidos}

Partindo das inferências dos licenciandos, de como planejar, como ensinar os conceitos matemáticos, a intervenção docente se direciona em apresentar algumas possibilidades de ensinar matemática na Educação Básica, mais especificamente no Ensino Fundamental. As possibilidades são entendidas a partir da organização de atividades de ensino, utilizando de materiais manipulativos (embalagens, caixa de bombons), de instrumentos de medida (régua), tecnologias informáticas (softwares Régua e Compasso e Poly), modelagem e investigação matemática.

As atividades de ensino fazem uso dos recursos didáticos (PAIS, 2006) abordados anteriormente, com o objetivo de desencadear conceitos matemáticos atrelados a tais atividades. Nesta perspectiva, a intenção, neste artigo, é contemplar as atividades planejadas e que foram desenvolvidas com a turma de licenciandos na disciplina de Prática de Ensino III: Matemática no Ensino Fundamental, na Licenciatura em Matemática da referida universidade.

\section{Atividade 01}

\subsection{Embalagens, o que podemos explorar/investigar?}

Que formas geométricas estão presentes nas embalagens?

Sólidos geométricos: prisma, pirâmide, cilindro, esfera, cone?

Sólidos: visualização, planificação e verificação de tipos no Softwware Poly.

\subsection{Prismas}

Prismas: o que são?

Prismas de bases: triangular, retangular, quadrangular, pentagonal, hexagonal Cada canto, em linguagem matemática:...

Cada dobra, em linguagem matemática:...

Cada lado, em linguagem matemática:...

Prisma de base triangular: passagem do tri para o bidimensional (geometria espacial $\mathrm{p} /$ plana)

\subsection{Interação com o software}

Software Régua e Compasso - recurso computacional de geometria dinâmica: características 
Construção de triângulo qualquer. Como posso desenhar? Utilizando o quê? Quais procedimentos?

Construção de um triângulo equilátero, a partir das medidas dos lados. Como podemos proceder?

Construção de um triângulo equilátero, a partir dos instrumentos régua e compasso virtuais.

Construção de um quadrado e de um retângulo, a partir dos instrumentos régua e compasso virtuais.

\subsection{Formalização dos conceitos presentes nas atividades}

Expresse, com suas palavras, o entendimento do conceito de triângulo (condições de existência);

Como podemos desenhar um triângulo equilátero? Descreva os procedimentos, formalizando o conceito de triângulo equilátero;

Qual a diferença entre a construção com régua e compasso virtuais e o desenho feito manualmente?

\subsection{Um olhar para a tri e bidimensionalidade a partir de uma "caixa de bombons"}

(Notas do planejamento do professor estagiário - 23/04/2009).

$\mathrm{Na}$ atividade 01, inicialmente, foi feita uma discussão com os licenciandos a respeito das embalagens, questionando-os em relação às formas, ou seja, o que as embalagens revelam em termos de sólidos geométricos. O diálogo estabelecido proporcionou o estabelecimento de conexões entre as embalagens e a visualização dos sólidos geométricos. Esta visualização aconteceu através do software Poly, recurso tecnológico destinado ao trabalho com geometria espacial.

Com o entendimento dos sólidos geométricos, a discussão dirigida (pelo professor estagiário) concentrou-se na abordagem dos prismas, que são sólidos geométricos com características próprias. Os prismas de base retangular, quadrangular e retangular foram mais discutidos do que os de base pentagonal e hexagonal, pelo fato de que, na sequência, faríamos discussões a respeito das figuras planas: triângulo, retângulo e quadrado. Aspectos também abordados a partir das embalagens foram dobras, cantos e lados, que, em linguagem matemática, representam vértices, arestas e faces respectivamente.

Os prismas representam a geometria espacial ou o espaço tridimensional. A passagem para a bidimensionalidade, que representa a geometria plana, foi feita com o recurso tecnológico de geometria dinâmica - software Régua e Compasso. Por exemplo, ao considerar, um prisma de base triangular, no software, utilizamos somente uma face para análise, ou seja, as figuras geométricas consideradas planas (triângulo, quadrado, retângulo). 
Após as discussões com os licenciandos sobre os conceitos anteriormente descritos, iniciamos o processo de formalização dos conceitos matemáticos envolvidos na atividade 01. Consideramos a formalização essencial, pois, por si só, a atividade não promove a elaboração conceitual.

A processualidade presente nesta atividade desencadeou o trabalho com a "caixa de bombons", que teve como objetivo calcular a quantidade de material usada para sua fabricação. Para tanto, foi necessário o cálculo da área das figuras planas (retângulos), que formam a referida embalagem, para, posteriormente, elaborar-se o modelo matemático que calcula a área de qualquer prisma de base retangular, ou seja, determinar a quantidade de material usado para a fabricação da "caixa de bombons" (alguns detalhes da atividade são apresentados no próximo tópico).

A atividade 02 é entendida em dois momentos: o primeiro foi a discussão de um artigo sobre o ensino de álgebra com o uso do computador, com a intenção de complementar a atividade 01 , pois o referido artigo desenvolve um relato de uma vivência em sala de aula no Ensino Fundamental. A imbricação dos blocos de conteúdos, campos da matemática para o Ensino Fundamental destacados nos PCN descortinam o segundo momento, em que os licenciandos registraram seus entendimentos e elaboraram uma atividade, mediante reflexões realizadas pela intervenção docente.

\section{Atividade 02}

\subsection{Discussão e análise do artigo - turma e professor}

- PASCHOAL, Fernando Lorenzo; LANZONI, André Corrêa. Investiga-ções em Álgebra com o Uso do Computador. In: FIORENTINI, Dario; CRISTOVÃO, Eliane Matesco (orgs.). Histórias e Investigações de/em Aulas de Matemática. Campinas, SP: Alínea, 2006. p. 173-190.

\subsection{Sistematização das atividades - blocos de conteúdos e campos da matemática}

Considerando os conceitos abordados nas atividades, explicite os blocos de conteúdos e os campos da matemática, percebendo a interação possível entre ambos.

\subsection{Entendimentos dos aspectos metodológicos/recursos para ensinar e aprender matemática}

De forma sucinta, relate a importância das tecnologias informáticas e da modelagem matemática, recursos utilizados nas atividades desenvolvidas e indicados pelos PCN para ensinar e aprender matemática.

\subsection{Eu, futuro professor (a), como planejo uma atividade para ensinar matemática no Ensino Fundamental?}

Considerando os softwares gratuitos disponíveis na Internet para ensinar e aprender matemática, escolha um software e elabore uma pequena atividade, 
que poderia ser desenvolvida para tratar de um conceito matemático, presente em um dos campos e blocos de conteúdos propostos pelos PCN. A intenção é você colocar-se como futuro professor de matemática de Ensino Fundamental.

(Notas do planejamento do professor estagiário - 30/04/2009).

Diante destes encaminhamentos, para efeitos de análise, considerando os itens 2.2, 2.3 e 2.4 da atividade 02, compartilhamos, no próximo tópico, fragmentos extraídos dos registros dos licenciandos. A intenção é promover a reflexão sobre a potencialidade das atividades de ensino para estabelecer relações de blocos e campos da matemática, apontadas pelos licenciandos. A contribuição é mostrar a possibilidade de imbricar os conteúdos/conceitos de diferentes campos da matemática do Ensino Fundamental. Em outras palavras, a análise a seguir recorre à articulação entre os blocos de conteúdos nos diferentes campos da matemática, presentes nos PCN, diante da reflexão sobre/com as atividades de ensino. E, por último, retratar como os licenciandos planejaram uma atividade, a qual reflete os encaminhamentos e reflexões da intervenção docente.

\section{A potencialidade das atividades de ensino: análise dos registros de licenciandos}

As atividades de ensino trabalhadas com os licenciandos complementaram as aulas da professora titular da disciplina de Prática de Ensino III: Matemática no Ensino Fundamental. Tal complementaridade é entendida no sentido de contribuição para a formação inicial e a futura atuação dos licenciandos como professores de matemática na Educação Básica.

Para atingir esse objetivo foram elaboradas atividades de ensino, em que os licenciandos vivenciaram e dialogaram sobre conceitos matemáticos do Ensino Fundamental trabalhados, utilizando embalagens (material manipulativo), tecnologias informáticas (softwares), modelagem e investigações matemáticas. "O uso de materiais didáticos é uma estratégia importante porque contribui na construção da abstração e da generalização" (PAIS, 2006, p. 145-146). O entendimento de Pais (2006) é passível de percepção nos registros dos licenciandos.

Apresentamos registros de licenciandos, coletados a partir da atividade 02. A articulação feita pelos licenciandos entre os campos e os blocos de conteúdos de matemática apontados pelos PCN, considerando os recursos didáticos (tecnologias informáticas, modelagem matemática, embalagens, investigações), reflete a multiplicidade de entendimentos, isto é, a riqueza dos registros é estabelecida pela singularidade (de cada grupo de licenciandos) e, sobretudo, pela maneira de compreender o ensino de matemática. 
A sistematização das atividades foi desencadeada a partir de três questões. A primeira: Considerando os conceitos abordados nas atividades, explicite os blocos de conteúdos e os campos da matemática, percebendo a interação possivel entre ambos.

Entendemos que por meio da atividade com a caixa de bombons, podemos explorar/construir diversos conceitos matemáticos, pois as medidas se fazem a partir de objetos concretos, que possuem uma forma, a qual expressamos através dos números, mas que também podemos expressar através de formas geométricas.

No momento em que fomos desafiados a pensar quais conceitos estavam presentes na atividade que havíamos feito, notamos que precisamos mobilizar alguns conhecimentos para conseguir dizer quais conceitos estavam envolvidos naquela atividade, como por exemplo, a aritmética, no momento que somamos as áreas de cada retângulo, para obtermos a área total daquela caixa, assim como a álgebra, por meio do modelo matemático que usamos para chegar na resposta (Grupo 012 - 07/05/2009, grifo dos licenciandos).

Os registros denotam que os licenciandos conseguiram olhar para os conceitos que emergiram das atividades, pois concatenaram os blocos de conteúdos (grandezas e medidas, espaço e forma e números e operações) e os campos da matemática (álgebra, geometria e aritmética), à medida que relataram os procedimentos da atividade com a "caixa de bombons". Para isso, os licenciandos refletiram sobre dois momentos das atividades: no primeiro, relacionam os conceitos com os blocos de conteúdos, e, no segundo, fazem referência aos campos da matemática.

O entendimento de outro grupo de licenciandos é semelhante, porém, o grupo 02 explicita mais um dos blocos de conteúdos, que é o tratamento da informação. A percepção dos blocos de conteúdos e campos através das atividades, cada grupo a seu modo, determinou a interação existente entre eles, principalmente, pelo reolhar os procedimentos das atividades.

Os conceitos abordados nas últimas aulas tratam de todos os blocos de conteúdos do Ensino Fundamental. Através do cálculo das áreas das diferentes figuras geométricas, por exemplo, todos os blocos de conteúdos são visualizados: para o cálculo do valor numérico da área entraremos no bloco de números e operações. O bloco espaço e forma é visto quando falamos das figuras geométricas e por fim o bloco tratamento da informação é tratado através da coleta, organização e interpretação dos dados.

Ainda utilizando como exemplo o cálculo das áreas percebemos que os campos da matemática também estão presentes nesta atividade, onde utilizamos a geometria para definir as formas geométricas, a álgebra para expormos a

\footnotetext{
${ }^{2}$ Os registros foram feitos por grupo de licenciandos, chamados por Grupo 01, 02 e 03.
} 
fórmula das determinadas áreas e aritmética para chegar a um resultado numérico.

Concluímos então que os blocos de conteúdos e os campos da matemática estão totalmente interligados no processo de aprendizagem.

(Grupo 02 - 07/05/2009, grifo dos autores).

Os procedimentos para a realização da atividade da "caixa de bombons" é detalhado pelo Grupo 03, ao mesmo tempo em que imbricam alguns blocos de conteúdos e os campos da matemática. Acreditamos que "O ensino de Matemática na escolaridade fundamental consiste em partir de conhecimentos, que envolvem números, medidas, figuras geométricas e outros conceitos, de maneira que esses elementos estejam articulados com a vivência do aluno" (PAIS, 2006, p. 65). Nesse sentido, ressaltamos que conhecer os campos aritmético, algébrico e geométrico, saber diferenciá-los e, ao mesmo tempo, articulá-los a partir dos blocos (números e operações, grandezas e medidas, espaço e forma, no caso do Grupo 3) representam uma tarefa fundamental no processo de ensinar matemática, em particular dos licenciandos em matemática.

Partimos de uma embalagem observamos o espaço e a forma de um paralelepípedo após planificarmos a mesma, desconsiderando as bordas, observamos e medimos as dimensões das faces e das bases. Considerando que todas as faces são figuras retangulares, calculamos a área de cada uma delas, utilizando a relação de cálculo de área de figuras retangulares (base x altura), substituímos nas fórmulas as medidas encontradas multiplicando cada uma delas por dois e finalmente somando as medidas encontradas para chegar ao resultado de quanto papel foi gasto para construir a embalagem, utilizando assim o bloco de números e operações. Considerando as dimensões substituímos os números por variáveis chegando num modelo algébrico para quaisquer dimensões (Grupo 03 - 07/05/2009, grifo dos autores).

O Grupo 04, sem detalhar as atividades, apenas mencionou as relações entre campos e blocos de conteúdos. Ou seja, o grupo não mostrou por meio desta narrativa uma compreensão com a atividade e, de certa forma, apenas relata a relação entre os campos e blocos de conteúdos, de forma genérica, sem aprofundar os procedimentos realizados e, possivelmente, refletidos por meio das atividades propostas pelo professor estagiário.

Quando trabalhamos com figuras geométricas, é possível evidenciar os conteúdos presentes nos PCN, nos blocos que envolvem espaço e forma, números e operações e tratamento da informação desenvolvendo os conceitos de álgebra, geometria e aritmética (Grupo 04 - 07/05/2009).

As atividades foram desenvolvidas utilizando recursos e processos metodológicos, a exemplo, as tecnologias informáticas e a modelagem matemática. 
Diante disso, apresenta-se a segunda questão da sistematização, a saber: $D e$ forma sucinta, relate a importância das tecnologias informáticas e da modelagem matemática, recursos utilizados nas atividades desenvolvidas e indicados pelos PCN para ensinar a aprender matemática.

De modo geral modelagem matemática é conceituada como a aplicação da matemática em outras áreas do conhecimento, ou seja, modelagem matemática é um ambiente de aprendizagem no qual os alunos são convidados a problematizar e investigar, por meio da matemática, situações com referência na realidade.

A informática facilita, para os alunos, a visualização da linguagem gráfica e de novas formas de representação, permitindo novas estratégias de abordagem de variados problemas do cotidiano, facilitando assim a percepsão dos conceitos matemáticos, auxiliando tanto o professor no momento de expor sua ideia de aula, bem como o aluno quando este forma os conceitos de matemática.

Outro fator importante da utilização da informática na aprendizagem da matemática é o grande ganho de tempo para a realização de uma determinada tarefa, como podemos verificar na aula onde utilizamos o software Régua e Compasso para elaborar conceitos e construção das figuras foi bem menor do que se as mesmas fossem manuscritas (Grupo 02 - 07/05/2009, grifo dos autores).

O entendimento dos licenciandos do Grupo 02 contempla alguns aspectos (grifos) fundamentais para ensinar e aprender matemática. Os recursos usados nas atividades possibilitaram a este grupo pensar e estabelecer de forma genérica relações e interações que a modelagem matemática e as tecnologias informáticas podem articular. O Grupo 02 destaca a relação com o tempo, que pode ser diferente nas construções com tecnologias informáticas, em particular, por meio do uso de um software de geometria dinâmica, além de pontuar que novas formas de representação podem ser feitas, o que amplia as possibilidades de significação dos conceitos matemáticos.

A partir dos aspectos abordados pelo Grupo 02, entrelaçamos as relações estabelecidas pelo Grupo 01, que dialoga com os PCN para entender/refletir/ problematizar os procedimentos e recursos presentes ou decorrentes das atividades realizadas.

O computador é um instrumento que auxilia na visualização, agilidade e precisão na aplicação de modelos matemáticos. Porém, é necessário que antes se desenvolva o modelo matemático e se conceba uma atividade, para depois se utilizar o computador. Este vem complementar um aspecto essencial da aprendizagem matemática que é a manipulação e o "se dar conta" das relações e resultados existentes num determinado problema em estudo, que se dá de forma especial "botando a mão na massa", nos objetos concretos. 
Ambas as atividades foram significativas, pois por meio destas, conseguimos trabalhar a linguagem matemática e também trabalhar a linguagem coloquial, tornando o ensino mais contextualizado, e passível de entendimento, desse modo conforme os PCN.

“[...] um conhecimento só é pleno se for mobilizado em situações diferentes daquelas que serviram para lhe dar origem. Para que sejam transferíveis a novas situações e generalizados, os conhecimentos devem ser descontextualizados, para serem novamente contextualizados em outras situações. Mesmo no ensino fundamental, espera-se que o conhecimento aprendido não fique indissoluvelmente vinculado a um contexto concreto e único, mas que possa ser generalizado, transferido a outros contextos" (BRASIL, 1998, p. 36).

No momento que se trabalha com atividades diferenciadas, como as que trabalhamos na aula possibilitou-se a contextualização de alguns conceitos, pois "saímos" daquele entendimento abstrato dos conceitos de álgebra, aritmética entre outros (Grupo 01 - 07/05/2009, grifo dos autores).

A contextualização é o aspecto central do registro feito pelo Grupo 01, pois os licenciandos consideraram que a modelagem e os recursos computacionais podem possibilitar atividades diferenciadas, dando sentido aos conceitos matemáticos que são, muitas vezes, trabalhados de forma abstrata, sem conexão com o cotidiano dos sujeitos. Segundo Pais (2006, p. 63) "a contextualização do saber torna-se uma condição imprescindível", implicando "inserir os conceitos em situações nas quais o aluno tem maiores condições de compreender o sentido do saber" (PAIS, 2006, p. 63).

As atividades trabalhadas nessa intervenção docente, entre outras aspirações, tiveram como objetivo principal refletir (com os licenciandos) possibilidades de tratamento dos conceitos matemáticos do Ensino Fundamental. As reflexões feitas pelos licenciandos nas questões, buscando aproximações com os PCN, os colocam como sujeitos em processo de aprendizagem, ao mesmo tempo em que projetam sua atuação como professores da Educação Básica. É importante salientar que este artigo dirige seu olhar para a vivência de uma intervenção docente no Ensino Superior, na forma de prática de estágio e, por isso, inclui um processo de idas e vindas com os temas tratados - neste caso, os dos PCN - pela professora titular, nos próprios registros dos licenciandos, observando os saberes construídos/mobilizados por eles ao longo da disciplina.

Nessa perspectiva, a terceira questão para análise - Considerando os softwares gratuitos disponiveis na Internet para ensinar e aprender matemática, escolh a um software e elabore uma pequena atividade, que poderia ser desenvolvida para ensinar um conceito matemático, presente em um dos campos e blocos de conteúdos propostos pelos PCN. A intenção é você se colocar como futuro professor de matemática de Ensino Fundamental - permitiu aos licenciandos planejar uma atividade, retomando as discussões feitas em sala de aula. 
A intenção desta atividade é mostrar alguns encaminhamentos feitos pelos licenciandos, marcando as relações entre os blocos de conteúdos e os campos da matemática. Para isso, apresentamos uma das atividades elaborada por um dos grupos de licenciandos.

\section{Atividade utilizando o Excel}

A pergunta da pesquisa será a seguinte: Qual o jogador de futebol que percorre maior distância em campo durante um mês?

Serão disponibilizados os seguintes dados: dimensões do campo oficial (120m $\mathrm{x} 90 \mathrm{~m})$ e a quantidade de vezes que cada jogador atravessa cada uma dessas dimensões em quatro jogos diferentes. Primeiramente os alunos serão convidados a formular o modelo algébrico que dará a quantidade de metros percorridos por cada jogador durante um jogo $(x=120 \mathrm{n}+90 \mathrm{~m})$. Depois aplicarão este modelo matemático em cada situação e farão a média para descobrir qual jogador percorre a maior distância em um jogo, todos estes dados obtidos serão colocados na tabela preparada no Excel que está em anexo. Ainda serão provocados a construir o gráfico do desempenho mensal de cada jogador e o gráfico com o comparativo das médias percorridas dos jogadores, utilizando os recursos do software.

Com esta atividade serão contemplados os blocos de números e operações, grandezas e medidas e tratamento da informação, adentrando os campos matemáticos da álgebra, aritmética e estatística. Certamente o contexto da atividade gerará interesse nos alunos, principalmente para aqueles que gostam de futebol, estimulando os alunos a verem a matemática como algo útil e aplicável no seu dia-a-dia. E pelo interesse no tema, há uma grande oportunidade de potencializar a capacidade de aprendizagem dos alunos em temas de maiores dificuldades como a álgebra (Grupo 01 - 07/05/2009, grifo dos licenciandos).

O planejamento da atividade apresenta conexões com o cotidiano, pois o tema escolhido é conhecido e possivelmente mobilizará os estudantes da Educação Básica. A elaboração da atividade faz uso da modelagem e da planilha eletrônica Excel, promovendo o entrelaçamento dos blocos de conteúdos (números e operações, grandezas e medidas e tratamento da informação) e campos da matemática (aritmética, álgebra e geometria). Os procedimentos delineados para a atividade compreendem o ensino da matemática inter-relacionado, pois, geralmente, aritmética, álgebra, geometria e, ainda, o Grupo 01 menciona a estatística, são trabalhadas em compartimentos, ou seja, sem conexão entre campos e blocos de conteúdos. A atividade com a planilha descortina ensinar (ou a pretensão de ensinar) matemática de acordo com a proposição dos PCN, relacionando os conceitos, propiciando sentidos e significados para a matemática no Ensino Fundamental. Segundo Pais (2006, p. 90), "as articulações produzem significado 
para o conhecimento. Quanto mais intensas elas forem, tanto mais sentido terá um conteúdo educacional".

Neste tópico de análise, abordamos como as atividades de ensino foram recebidas pelos licenciandos e como elas representam não só um aspecto de planejamento, mas como a atividade de ensino, atrelada ao uso de recursos didáticos, pode culminar em discussões sobre os saberes disciplinar e curricular (TARDIF, 2002) envolvidos. E, além disso, como a mobilização dos licenciandos para a elaboração de uma atividade remete a posicioná-los como futuros professores de matemática. As relações estabelecidas podem ser refletidas quando tratamos de processos de ensinar e de aprender matemática.

\section{Algumas considerações}

A intervenção docente realizada na Prática de Ensino III: Matemática no Ensino Fundamental, considerando as observações de aula e, sobretudo, as aulas proferidas pelo professor estagiário, descortina um momento singular na própria formação profissional do exercício da docência. Por outro lado, a vivência desse processo de intervenção implica a ressignificação de saberes, de estratégias, de encaminhamentos metodológicos escolhidos pelo professor e, possivelmente, sugere implicações para a aprendizagem dos licenciandos. Além disso, a intervenção possibilitou refletir a formação inicial como um espaço de discussão de saberes, práticas que possam sustentar a atuação dos licenciandos na Educação Básica, seja ela, durante a licenciatura (na forma de disciplina de Prática de Ensino e/ou estágios) ou na futura profissão.

Especificamente, uma das contribuições refletidas neste ensaio é a possibilidade de articulação dos conceitos, campos e blocos de conteúdos na área de matemática. Esta articulação foi percebida nos registros expressos pelos licenciandos, na medida em que refletiram sobre os procedimentos e relações estabelecidas com as atividades trabalhadas, pois, "quanto mais intensas forem a interatividade e a articulação, mais significativa será a aprendizagem” (PAIS, 2006, p. 52).

As atividades foram desenvolvidas com recursos didáticos indicados pelos PCN, dentre eles, a modelagem matemática, investigações matemáticas e as tecnologias informáticas. Para um grupo de licenciandos as tecnologias informáticas, no caso, o software Régua e Compasso apresentou possibilidades de tratamento de conceitos matemáticos, não como meras ferramentas, mas como recursos que podem produzir saberes quando pensamos/tratamos em ensino e aprendizagem de matemática. 
Conhecer o software Régua e Compasso, e como trabalhar algumas atividades, entendendo que é possível trabalhar com metodologias computacionais visando à aprendizagem significativa, e não pensando apenas na inclusão digital, que muitas vezes quando se fala em trabalhar com alguma atividade computacional nas escolas, nos remetemos a pensar na inclusão e não no ensino/ aprendizagem de conceitos necessários para adquirir conhecimento e sair da "rotina” (Grupo 01 - 07/05/2009, grifo dos autores).

Os aspectos salientados pelos licenciandos indicam a potencialidade do software, pois no ensino de geometria a incorporação de recursos tecnológicos em sala de aula "[...] amplia as formas tradicionais de representação dos conceitos, porque incorpora elementos como cor, som e movimento e cria representações dinâmicas [...]" (PAIS, 2006, p. 72). As representações dinâmicas são possíveis em função do uso de softwares dessa natureza, o que pode ampliar as possibilidades de tratamento de propriedades de figuras geométricas planas fazendo uso da movimentação permitida pelo recurso.

Para além da geometria, os licenciandos estabeleceram formas de articulação entre a álgebra, a aritmética e a estatística, transitando entre os blocos de conteúdos (espaço e forma, grandezas e medidas, números e operações e tratamento da informação), refletindo, ressignificando e possivelmente aprendendo ou significando conceitos matemáticos do Ensino Fundamental, os quais representam o saber disciplinar, aliado aos recursos, planejamento e objetivos que estão vinculados a esse saber (TARDIF, 2002).

Assim, entendemos que as transições e as conexões entre os campos algébrico, aritmético e geométrico, principalmente, permearam parte dos registros dos licenciandos. Também, a presença dos blocos de conteúdos foi destacada e tramada pelas atividades planejadas pelo professor estagiário, bem como na atividade produzida pelos licenciados. Nesse viés, acreditamos que a potencialidade dinâmica da atividade concomitantemente com a intenção do professor em mobilizar distintos campos e blocos de conteúdos matemáticos representa um dos caminhos de produzir saberes no Ensino Superior e também na Educação Básica.

O movimento estabelecido, neste artigo, enseja entender a Educação Matemática como "[...] uma síntese de produção individual e coletiva, resultante de várias articulações, entre as quais enumeramos: intuições, momentos, experiências, teorias, condições locais, situações vivenciadas, referências históricas" (PAIS, 2006, p. 67). Para tanto, salientamos que nossa intenção foi compreender, refletir e socializar, como ocorreu a vivência de intervenção docente, na forma de estágio de docência na Licenciatura em Matemática, relatando a observação em sala de aula, o planejamento do professor estagiário e a intervenção docente. 
Estabelecemos, em tais momentos, algumas relações com os processos de ensinar e aprender matemática, como parte da formação dos professores de matemática, na perspectiva de reforçar que pressupostos teóricos e a prática estão imbricados, tanto na intervenção docente como no desenvolvimento deste artigo.

Em suma, o processo de relatar a vivência de uma intervenção docente apontou um movimento de contribuição para a formação inicial de professores de matemática. Acreditamos que a vivência e a experiência com atividades de ensino, com o planejamento de atividades e com a reflexão na forma de registros permitem a mobilização de saberes disciplinares, curriculares e pedagógicos (TARDIF, 2002), os quais podem fundamentar a formação do futuro professor de matemática e contribuir significativamente na constituição de seus saberes docentes.

\section{Referências}

BAIRRAL, M. A. Aulas diferentes de Matemática: o caso dos ângulos. Presença Pedagógica, Belo Horizonte, v. 8, n. 45, p. 51-57, maio/jun. 2002.

BRASIL. Ministério da Educação. Secretaria de Educação Fundamental. Parâmetros Curriculares Nacionais: Matemática - Ensino Fundamental - $3^{\circ}$ e $4^{\circ}$ Ciclos. MEC: Brasília, 1998.

PAIS, L. C. Ensinar e Aprender Matemática. Belo Horizonte: Autêntica, 2006.

PASCHOAL, F. L.; LANZONI, A. C. Investigações em álgebra com o uso do computador. In: FIORENTINI, D.; CRISTOVÃO, E. M. (Orgs.). Histórias e investigações de/em aulas de Matemática. Campinas, SP: Alínea, 2006. p. 173-190.

PAZUCH, V. Produção e mobilização de saberes a partir das práticas de professoras que ensinam Matemática com tecnologia informática. 2010. 127 f. Dissertação (Mestrado em Educação nas Ciências) - Universidade Regional do Noroeste do Estado do Rio Grande do Sul, Ijuí, 2010.

PIRES, C. M. C. Currículos de Matemática: da organização linear à idéia de rede. São Paulo: FTD, 2000.

- Implementação de inovações curriculares em matemática e embates com concepções, crenças e saberes de professores: breve retrospectiva histórica de um problema a ser enfrentado. Revista Iberoamericana de Educación Matemática, n. 12, p. 5-26. dez. 2007.

PPP. PROJETO POLÍTICO PEDAGÓGICO. Projeto Político Pedagógico do Curso de Licenciatura em Matemática. 2009.

TARDIF, M. Saberes docentes e formação profissional. Petrópolis: Vozes, 2002.

Recebido em 17/02/2012

Aceito em 10/09/2012 